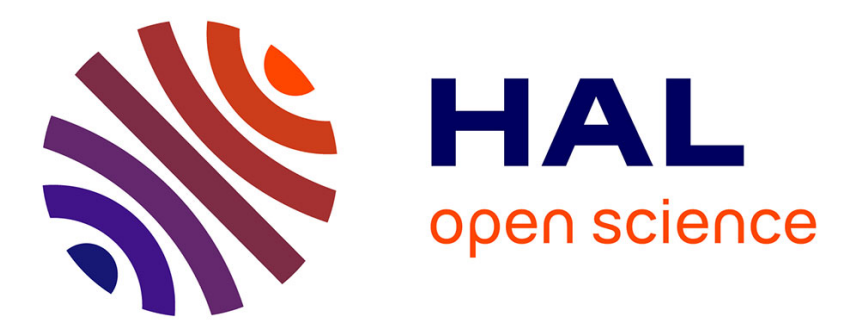

\title{
FEEDBACK CONTROL OF COAXIAL ATOMIZATION BASED ON THE SPRAY LIQUID DISTRIBUTION
}

Rodrigo Osuna-Orozco, Nathanaël Machicoane, Peter Huck, Alberto Aliseda

\section{- To cite this version:}

Rodrigo Osuna-Orozco, Nathanaël Machicoane, Peter Huck, Alberto Aliseda. FEEDBACK CONTROL OF COAXIAL ATOMIZATION BASED ON THE SPRAY LIQUID DISTRIBUTION. Atomization and Sprays, 2019, 10.1615/AtomizSpr.2019031766 . hal-02519246

\author{
HAL Id: hal-02519246 \\ https://hal.science/hal-02519246
}

Submitted on 26 Mar 2020

HAL is a multi-disciplinary open access archive for the deposit and dissemination of scientific research documents, whether they are published or not. The documents may come from teaching and research institutions in France or abroad, or from public or private research centers.
L'archive ouverte pluridisciplinaire HAL, est destinée au dépôt et à la diffusion de documents scientifiques de niveau recherche, publiés ou non, émanant des établissements d'enseignement et de recherche français ou étrangers, des laboratoires publics ou privés. 


\title{
FEEDBACK CONTROL OF COAXIAL
}

\section{ATOMIZATION BASED ON THE SPRAY}

\section{LIQUID DISTRIBUTION}

\author{
Rodrigo Osuna-Orozco, ${ }^{1, *}$ Nathanael Machicoane, ${ }^{1}$ \\ Peter D. Huck, ${ }^{1}$ E Alberto Aliseda ${ }^{1}$ \\ ${ }^{1}$ Department of Mechanical Engineering, University of Washington, Seattle,
} WA, 98105

*Address all correspondence to: Rodrigo Osuna-Orozco, Department of Mechanical Engineering, University of Washington, Seattle,WA, 98105 ,E-mail: roo3@uw.edu

We demonstrate a novel implementation of real-time feedback control on the structure of the spray produced by a two-fluid coaxial atomizer. The ratio of angular to longitudinal gas flow rates, called swirl ratio, as well as the total amount of gas coflow are used as the actuation at the nozzle. The swirling and swirl-free gas flow rate are individually set by the control algorithm, with the control objective set based on an optical absorbance radial profile that is related to the liquid volume fraction across the spray. We analyzed the liquid volume fraction profiles measured in open loop by means of singular value decomposition and principal component analysis (PCA) and found that the different states of the spray across a wide range of operating conditions can be described with fidelity by three principal components. The control algorithm maps the resulting state PCA projections to the control variables. Real time control of the spray is achieved over a wide range of operating conditions (gas-to-liquid momentum $1-20$ and swirl ratios $0-1$ ).

KEY WORDS: real-time feedback control, two-fluid coaxial atomization, multiphase flow, Principal Component Analysis 


\section{INTRODUCTION}

2 Liquid sprays are involved in many environmental phenomena (e. g. ocean sprays) and engi-

3 neering processes (e. g. combustion fuel sprays, coating processes). The development of control

4 strategies for sprays has been of great interest for the fuel combustion community, as is evident

5 in numerous examples of active control for fuel combustors that have been documented in the

6 last couple of decades (Billoud et al., 1992; Coker et al., 2006; Conrad et al., 2007; Jones et al.,

7 1999; McManus et al., 1993; Muruganandam et al., 2005; Murugappan et al., 2003). However,

8 as indicated in a recent review (Arai, 2019), ample opportunities remain for the development of

9 new active control strategies for sprays (spray control is referred to here as closed-loop feedback

10 actuation on the atomization and droplet dispersion stages to achieve a particular spray structure,

11 droplet size and/or spatiotemporal distributions).

The response of coaxial two-fluid atomizers to a wide range of swirling and non-swirling gas co-flows has been investigated extensively (Aliseda et al., 2008; Eggers and Villermaux, 2008; Lasheras et al., 1998; Marmottant and Villermaux, 2004), providing the theoretical and experimental basis for this feedback control work. Additionally, over the last decade data reduction methods have been extensively applied for the reduced order description and control of fluid flows (Blanchard and Sapsis, 2019; Grenga et al., 2018; Hervé et al., 2012; Huang et al., 2017; Krolick and Owkes, 2018; Leclercq et al., 2019; Mohan and Gaitonde, 2017; Rabault et al., 2019; Rowley and Dawson, 2017; Schmid et al., 2011; Tallet et al., 2016). Here, we present a method to perform feedback closed-loop control of a spray atomizer where the control input consists of measurements of light attenuation across the depth of the spray at 10 gas diameters downstream of the nozzle and where the control actuation is on the swirl and no-swirl gas flow rates (defined over ranges that span the desired momentum ratios and swirl ratios of interest). The goal of this technical note is to demonstrate, for the first time, feasibility of real-time spray control in a two-fluid atomizer, using a three-parameter Principal Component Analysis (PCA) description of the state of the spray from fast measurements and a two-input control algorithm. 
1 2. SPRAY TRANSVERSE PROFILE ATTENUATION MEASUREMENTS

\section{2.1 Atomizer and flow loop}

3 An open-source two-fluid coaxial atomizer * designed to study atomization physics in a canon-

4 ical setting (Machicoane et al., 2018) is used in this experimental implementation of real-time

5 feedback control of a spray. The design produces reproducible laminar liquid and turbulent gas

6 streams that have been characterized extensively (Machicoane et al., 2019). The liquid is in-

7 jected through a straight circular duct and the condition of the liquid going into the atomization

8 is fully-developed laminar Poiseuille flow. The gas enters the nozzle through eight inlets per-

9 pendicular to the axis, four without angular momentum and four with with a tunable amount of angular momentum in the gas co-flow, referred to as the swirl ratio. The gas flow develops along the nozzle axis whose inner (the outer wall of the liquid duct) and outer surfaces are shaped with cubic splines to provide a smooth acceleration that ensures a gas velocity profile close to a top hat at the nozzle exit, with no flow detachment along its inner walls.

Two electro-valves control the gas flow rates for the no-swirl and swirl inlets independently (each line is then split into 4 ducts into the nozzle) and an additional electro-valve controls the liquid flow rate. Two views of the nozzle (drawings of side and plan views cut transversely along the nozzle axis and the gas inlet plane) are shown in figure 1 .

The relevant non-dimensional groups that we use to characterize this multiphase flow are: the swirl ratio $S R=Q_{n s} / Q_{s w}$, which compares the swirl gas flow rate, $Q_{s w}$, to the no-swirl gas flow rate, $Q_{n s}$, and the momentum ratio $M=\rho_{g} U_{g}^{2} / \rho_{l} U l^{2}$ that is based on the gas and liquid average velocity and density, $U_{i}=Q_{i} / A_{i}$ and $\rho_{i}$, where the subscripts $g$ and $l$ are used for gas an liquid respectively, and $A_{i}$ is the fluid area.

\subsection{Light attenuation measurements and analysis}

Light attenuation through line propagation across the spray is measured by a linear CCD camera

(Thorlabs model LC100) with a red LED panel providing a uniform source of illumination, in

*The atomizer design is made available to the community at
http://depts.washington.edu/fluidlab/nozzle.shtml

Volume x, Issue x, 2019 
a)

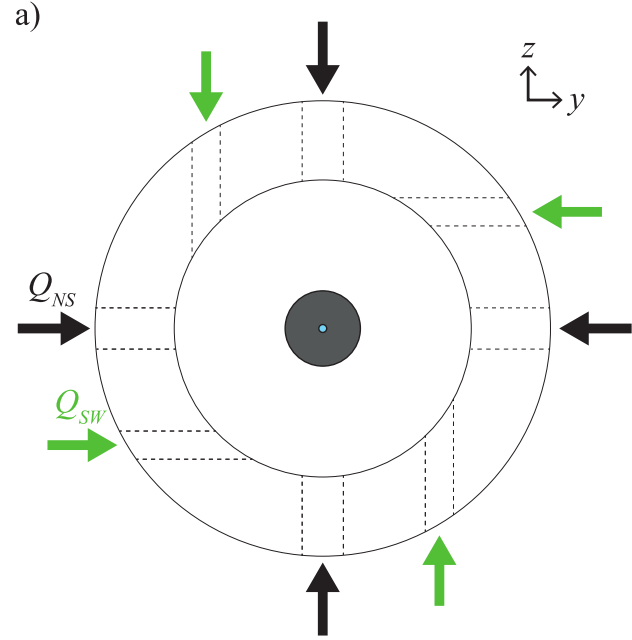

b)

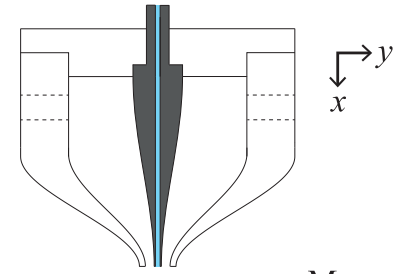

c)

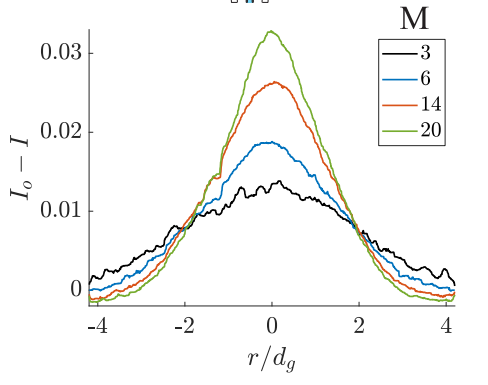

FIG. 1: (a) Transverse cut of the nozzle along the gas inlets plane showing the liquid channel in the middle and the eight inlets for gas. (b) Cross section of the nozzle along the liquid channel axis. (c) Representative samples for the absorbance profiles, in arbitrary units, at different momentum ratios in the absence of swirl.

1 a configuration analogous to shadowgraphy. Representative spray transverse profiles of light at-

2 tenuation, associated with liquid volume fraction, are shown in figure 1. Despite the low optical

3 density of the spray in the mid-field, the attenuation across the spray cross-section is of the order

4 of a few percent, which is well within the line camera 12-bit resolution and above the measure-

5 ment noise, which was characterized before data collection as 0.04 percent of the unattenuated

6 signal.

$7 \quad$ We study swirl ratios in the range 0 to 1 and momentum ratios in the range 2 to 20. Data

8 shown here spans this range adjusting the control inputs (no-swirl and swirl volume flow rates,

$9 Q_{n s}$ and $Q_{s w}$, respectively) within these limits. Light attenuation profiles, used as a surrogate

10 of the spray liquid volume fraction, were collected in open loop sequence. Said profiles were

11 analyzed using principal component analysis. PCA revealed that the three main modes serve as

12 a good basis to represent most of the energy in the observed shapes, as shown in figure 2.

13 The principal components identified as a basis to represent the light attenuation are normal-

14 ized to form an orthonormal basis onto which to project the instantaneously measured profiles.

15 As a result, the spray state that is the goal of the control algorithm, can be described as a spatial

16 profile using only three parameters. A two by three transfer function relates the 3 values that 

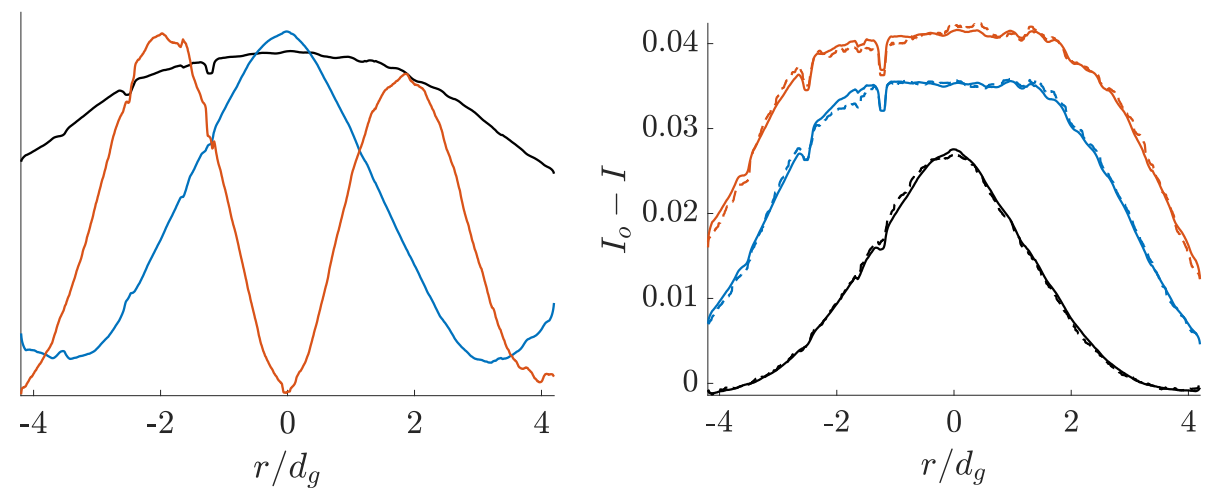

FIG. 2: (Left) First Three Principal Components in arbitrary units. (Right) Observed profiles (dashed lines) and principal component reconstructions (solid lines), for $M=13.6$ and $S R=0.2,0.5,0.8$ from bottom to top.

1 define the control goal to the 2 control variables. Given the projections onto the basis vectors, a

2 least-squares fit for the flow parameters produces a linear function of the projection parameters.

3 Details of the this process are given in appendix A.

\section{3. REAL-TIME FEEDBACK CONTROL IMPLEMENTATION}

\section{3.1 Control Algorithm and Performance}

6 The real-time control is performed by setting a goal profile in terms of its principal compo-

7 nent representation (any three values of the PCA basis, not a preset of values tested a-priori).

8 The control algorithm minimizes the root mean square error (RMSE) of the profile measured

9 instantaneously relative to the goal profile. This is achieved in two steps. First, an initial guess

10 based on the least squares fit indicates the goal for the swirl and no-swirl components of the

11 gas flow. Second, the magnitude of the change in both controls is adjusted by the magnitude of

12 the root mean square error. A proportional-integral-derivative controller (native Labview imple-

13 mentation) is used to control the proportional valves based on the flow meters and the computed

14 set-point for the flow rates. This process is iterated to attain a tolerance in the cost function (dif-

15 ference between goal and actual light attenuation profiles). A schematic of the control algorithm

16 is presented in figure 3.

Volume x, Issue x, 2019 


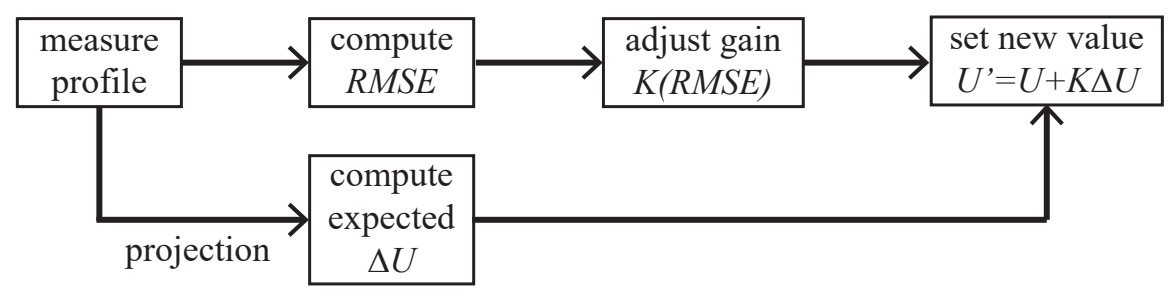

FIG. 3: Control diagram for our proposed method.

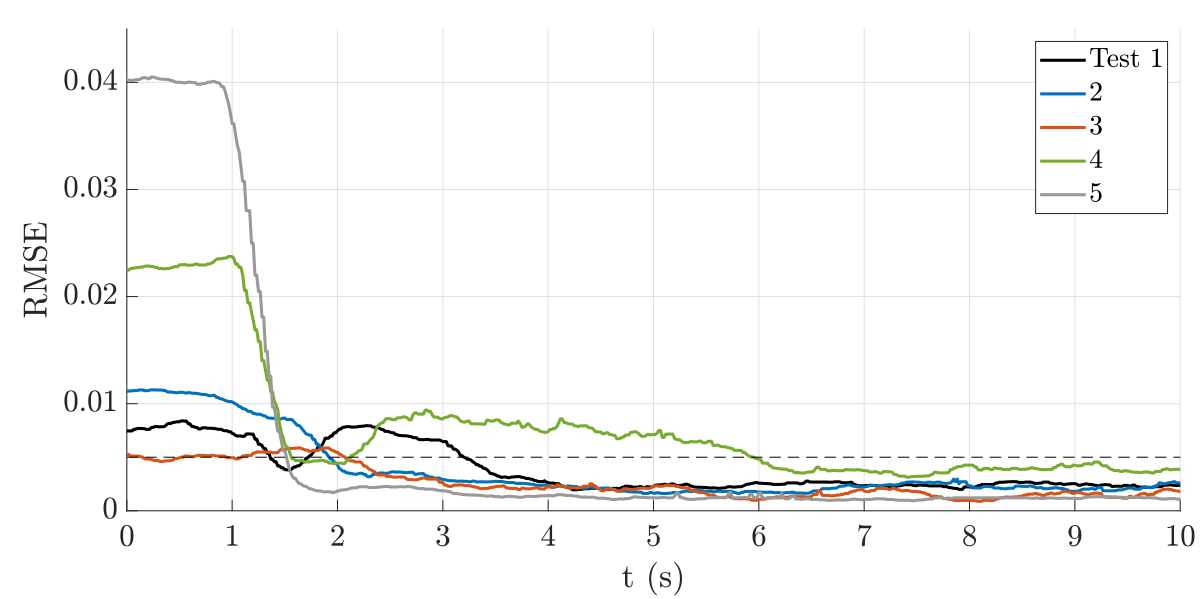

FIG. 4: Root mean square errors along time, between the goal profile and the instantaneous profile for five cases corresponding to videos in supplementary material.

1 The control algorithm is tested on a variety of random conditions (see videos in supple-

2 mentary materials), showing quick and robust convergence to each of the random goal profiles

3 (figure 4). The proportional valves used for both gas inputs have response times of the order of

4 a fraction of a second, and this sets the characteristic time required for the system to stabilize.

5 Interestingly, in some cases the convergence is non-monotonic as both control parameters are

6 varied. The RMSE increases as the control changes both inputs semi-independently, and then

7 drastically diminish as one control parameter reaches its optimum value, with the control al-

8 gorithm then refining convergence by fine-tuning the other input in small increments. This can

9 cause large changes of the spray features, which explain why the RMSE can increase before

10 decreasing to below tolerance. 
4. CONCLUSIONS

2 We achieved real-time feedback control of a high momentum spray based on a low dimensional

3 representation of spray light attenuation that can be measured as a surrogate of liquid volume

4 fraction and processed in real-time. To the best of our knowledge, this is the first instance of the

5 implementation of such control in the literature. The control algorithm showed robust perfor-

6 mance and response times well-matched to the available actuation in this high-momentum spray

7 (in the order of fractions of a second). It is possible to rigorously correlate the light attenua-

8 tion profile to physically meaningful characteristics of the spray, such as liquid volume fraction,

9 opening the opportunity to use the proposed control strategy to maintain certain spray quality for

10 a variety of applications where quantitative goals (not random profiles) are well-defined. Future

11 work will focus on these aspects, as well as on implementing multiphysics control actuation,

12 such as electrohydrodynamic effects and acoustic forcing.

\section{ACKNOWLEDGMENTS}

This work was sponsored by the Office of Naval Research (ONR) as part of the Multidisciplinary University Research Initiatives (MURI) Program, under grant number N00014-16-1-2617. The views and conclusions contained herein are those of the authors only and should not be interpreted as representing those of ONR, the U.S. Navy or the U.S. Government.

\section{APPENDIX A. LINEAT LEAST SQUARES FIT OF CONTROL PARAMETERS}

We varied the values of the control parameters $Q_{n s}$ and $Q_{s w}$ so as to uniformly sample the momentum and swirl ratios of interest (as the spray physics are dominated by these nondimensional groups). The evolution of the principal component coefficients $v_{i}$ with $Q_{s w}$ and $Q_{n s}$ is roughly linear. Each control parameter can be varied independently of the other which justifies the use of a linear fit (e.g. $\left.v_{i} \approx a+b Q_{n s}+c Q_{s w}\right)$.

Figure A.5 shows the observed and predicted values of the swirling and non-swirling components of the gas flow rate based on a linear least squares fit to the principal component representation of the corresponding profiles. It can be observed that the fit reproduces the overall

Volume x, Issue x, 2019 

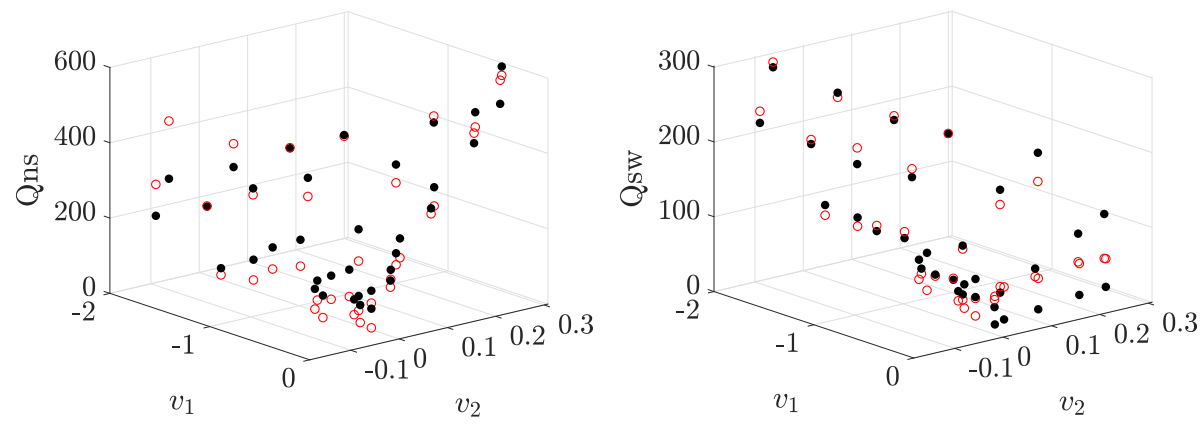

FIG. A.5: Observed (black dots) and predicted (red circles) values of the no-swirl (Left) and swirl (Right) gas flow rates.

1 trends reasonably well $\left(R^{2} \approx 0.9\right)$ and that it fails mostly for low values of the gas flow rate.

\section{REFERENCES}

3 Aliseda, A., Hopfinger, E., Lasheras, J., Kremer, D., Berchielli, A., and Connolly, E., Atomization of vis-

4 cous and non-newtonian liquids by a coaxial, high-speed gas jet. Experiments and droplet size modeling,

$5 \quad$ International Journal of Multiphase Flow, vol. 34, no. 2, pp. 161-175, 2008.

6 Arai, M., The Possibility of Active Attitude Control for Fuel Spray, Engineering, vol. 5, no. 3, pp. 519-534, 72019.

8 Billoud, G., Galland, M.A., Huu, C.H., and Candel, S., Adaptive Active Control of Combustion Instabilities, Combustion Science and Technology, vol. 81, no. 4-6, pp. 257-283, 1992.

10 Blanchard, A. and Sapsis, T.P., Stabilization of unsteady flows by reduced-order control with optimally time-dependent modes, Physical Review Fluids, vol. 4, no. 5, p. 053902, 2019. a liquid fueled combustor, Combustion Science and Technology, vol. 178, no. 7, pp. 1251-1261, 2006.

Conrad, T., Bibik, A., Shcherbik, D., Lubarsky, E., and Zinn, B., Feasibility of "intermittent" active control of combustion instabilities in liquid fueled combustors using a "smart" fuel injector, Proceedings of the Combustion Institute, vol. 31, no. 2, pp. 2223-2230, 2007.

17 Eggers, J. and Villermaux, E., Physics of liquid jets, Reports on Progress in Physics, vol. 71, no. 3, 2008.

Grenga, T., MacArt, J.F., and Mueller, M.E., Dynamic mode decomposition of a direct numerical simulation of a turbulent premixed planar jet flame: convergence of the modes, Combustion Theory and Modelling, vol. 22, no. 4, pp. 795-811, 2018. 
1 Hervé, A., Sipp, D., Schmid, P.J., and Samuelides, M., A physics-based approach to flow control using system identification, Journal of Fluid Mechanics, vol. 702, pp. 26-58, 2012.

3 Huang, G., Lu, W., Zhu, J., Fu, X., and Wang, J., A nonlinear dynamic model for unsteady separated flow control and its mechanism analysis, Journal of Fluid Mechanics, vol. 826, pp. 942-974, 2017.

5 Jones, C.M., Lee, J.G., and Santavicca, D.A., Closed-loop active control of combustion instabilities using 6 subharmonic secondary fuel injection, Journal of Propulsion and Power, vol. 15, no. 4, pp. 584-590, $7 \quad 1999$

8 Krolick, W. and Owkes, M., Primary Atomization Instability Extraction Using Dynamic Mode Decompo9 sition, Atomization and Sprays, vol. 28, no. 12, pp. 1061-1079, 2018.

10 Lasheras, J.C., Villermaux, E., and Hopfinger, E.J., Break-up and atomization of a round water jet by a high-speed annular air jet, Journal of Fluid Mechanics, vol. 357, p. S0022112097008070, 1998.

12 Leclercq, C., Demourant, F., Poussot-Vassal, C., and Sipp, D., Linear iterative method for closed-loop control of quasiperiodic flows, Journal of Fluid Mechanics, vol. 868, pp. 26-65, 2019.

Machicoane, N., Bothell, J.K., Li, D., Morgan, T.B., Heindel, T.J., Kastengren, A.L., and Aliseda, A., Synchrotron radiography characterization of the liquid core dynamics in a canonical two-fluid coaxial atomizer, International Journal of Multiphase Flow, vol. 115, pp. 1-8, 2019. control of a two-fluid coaxial atomizer, 14th Triennial International Conference on Liquid Atomization and Spray Systems, International Conference on Liquid Atomization and Spray Systems, 2018.

Marmottant, P. and Villermaux, E., On spray formation, Journal of Fluid Mechanics, vol. 498, pp. 73-111, 2004.

McManus, K., Poinsot, T., and Candel, S., A review of active control of combustion instabilities, Progress in Energy and Combustion Science, vol. 19, no. 1, pp. 1-29, 1993.

Mohan, A.T. and Gaitonde, D.V., Analysis of Airfoil Stall Control Using Dynamic Mode Decomposition, Journal of Aircraft, vol. 54, no. 4, pp. 1508-1520, 2017.

Muruganandam, T.M., Nair, S., Scarborough, D., Neumeier, Y., Jagoda, J., Lieuwen, T., Seitzman, J., and Zinn, B., Active control of lean blowout for turbine engine combustors, Journal of Propulsion and Power, vol. 21, no. 5, pp. 807-814, 2005.

Murugappan, S., Acharya, S., Allgood, D.C., Park, S., Annaswamy, A.M., and Ghoniem, A.F., Optimal

Volume x, Issue x, 2019 
control of a swirl-stabilized spray combustor using system identification approach, Combustion Science and Technology, vol. 175, no. 1, pp. 55-81, 2003.

3 Rabault, J., Kuchta, M., Jensen, A., Réglade, U., and Cerardi, N., Artificial neural networks trained through

4 deep reinforcement learning discover control strategies for active flow control, Journal of Fluid Mechan$5 \quad$ ics, vol. 865, pp. 281-302, 2019.

6 Rowley, C.W. and Dawson, S.T., Model Reduction for Flow Analysis and Control, Annual Review of Fluid $7 \quad$ Mechanics, vol. 49, no. 1, pp. 387-417, 2017.

8 Schmid, P.J., Li, L., Juniper, M.P., and Pust, O., Applications of the dynamic mode decomposition, Theo9 retical and Computational Fluid Dynamics, vol. 25, no. 1-4, pp. 249-259, 2011.

10 Tallet, A., Allery, C., and Leblond, C., Optimal flow control using a POD-based reduced-order model, Numerical Heat Transfer, Part B: Fundamentals, vol. 70, no. 1, pp. 1-24, 2016. 